\title{
PENGENALAN ECOBRICK DI SEKOLAH SEBAGAI UPAYA PENANGGULANGAN MASALAH SAMPAH
}

\author{
Muhammad Ikhsan ${ }^{1 *}$, Wilda Syam Tonra ${ }^{2}$ \\ 1,2,Universitas Khairun, Ternate, Indonesia \\ 1iccank@unkhair.ac.id \\ 2wildaunkhair@gmail.com
}

\begin{abstract}
Abstrak:
Sampah adalah salah satu masalah di Kota Ternate. Dengan meningkatnya aktivitas penduduk, maka sampah yang dihasilkan semakin banyak. Masalah sampah ini terutama sampah plastik karena sulit untuk terurai, berdampak negatif bagi kesehatan manusia dan lingkungan sekitar. Salah satu upaya untuk mengatasi masalah sampah adalah ecobrick. Ecobrick adalah teknik pengelolaan sampah plastik yang terbuat dari botol-botol plastik bekas yang didalamnya telah diisi berbagai sampah plastik hingga penuh kemudian dipadatkan sampai menjadi keras. Ecobrick merupakan salah satu upaya kreatif untuk mengelola sampah plastik menjadi benda-benda yang berguna, mengurangi pencemaran dan racun yang ditimbulkan. Kegiatan pengenalan ecobrick di sekolah ini perlu dilakukan untuk meningkatkan pemamahan dan kesadaran siswa SMPN 7 Kota Ternate agar mampu mengolah sampah menjadi sesuatu yang lebih berguna. Sehingga pada akhirnya siswa memahami bahwa sampah bukan hanya sekedar limbah, tetapi dapat dimanfaatkan kembali untuk kebutuhan manusia.
\end{abstract}

Kata Kunci: Ecobrick, Upaya Penanggulangan, Masalah Sampah

\section{Pendahuluan}

Kota Ternate merupakan kota yang terbentuk di bawah kaki gunung Gamalama dan dikelilingi oleh pulau-pulau kecil. Dalam waktu 5 tahun terakhir, Kota Ternate mengalami pertumbuhan penduduk yang pesat sehingga memicu pula perkembangan perdagangan, pendidikan, industri dan bisnis. Sejalan dengan itu, berbagai masalah pun terjadi. Salah satu masalah yang terjadi adalah masalah sampah. Menurut (Chandra, 2006) Jumlah penduduk bergantung pada aktivitas dan kepadatan penduduk, semakin padat penduduk, sampah semakin menumpuk karena tempat atau ruang untuk menampung sampah kurang. Oleh karena itu, semakin meningkatnya aktivitas penduduk, sampah yang dihasilkan semakin banyak. Adapun Sampah di Kota Ternate didominasi oleh sampah plastik akibat dari konsumsi masyarakat. Salah satu sumber sampah plastik di kota Ternate adalah sampah dari kantin sekolah. Sampah-sampah tersebut dimasukkan ke dalam karung untuk diangkut oleh 
mobil pengangkut sampah. Seringkali, Jika mobil pengangkut sampah terlambat datang, maka memicu penumpukan sampah.

Menurut Sucipto (2012), jenis-jenis sampah berdasarkan zat kimia yang terkandung di dalamnya dibedakan menjadi dua yaitu: 1) Sampah Organik Sampah organik berasal dari makhluk hidup, baik manusia, hewan, maupun tumbuhan. Sampah organik sendiri dibagi menjadi sampah organik basah dan sampah organik kering. Istilah sampah organik basah dimaksudkan sampah mempunyai kandungan air yang cukup tinggi seperti kulit buah dan sisa sayuran. Sementara bahan yang termasuk sampah organik kering adalah bahan organik lain yang kandungan airnya kecil seperti kertas, kayu atau ranting pohon dan dedaunan kering. 2) Sampah Anorganik Sampah anorganik bukan berasal dari makhluk hidup. Sampah ini berasal dari bahan yang bisa diperbaharui dan bahan yang berbahaya serta beracun. Jenis yang termasuk ke dalam kategori bisa didaur ulang (recycle) ini misalnya bahan yang terbuat dari plastik atau logam. Sampah kering non logam (gelas kaca, botol kaca, kain, kayu, dll) dan juga sampah lembut yaitu seperti sebu dan abu.

Chandra (2006) menyatakan dampak negatif sampah yaitu : 1) Dampak terhadap kesehatan a) Menjadikan sampah sebagai tempat perkembangbiakan vector penyakit seperti lalat, kecoa atau tikus b) Jumlah penyakit Demam Berdarah Dengue (DBD) akan meningkat karena vektor penyakit hidup dan berkembang biak dalam sampah kaleng ataupun ban bekas yang berisi air hujan c) Terjadi kecelakaan akibat pembuangan sampah sembarangan seperti luka akibat benda tajam seperti besi, kaca, dan sebagainya d) Gangguan psikosomatis atau penyakit yang melibatkan pikiran dan tubuh, di mana pikiran memengaruhi tubuh hingga penyakit muncul atau menjadi bertambah parah misalnya sesak napas, insomnia, stress, dan lain-lain. 2) Dampak terhadap lingkungan a) Estetika lingkungan menjadi kurang sedap dipandang mata b) Proses pembusukan sampah oleh mikroorganisme akan menghasilkan gasgas tertentu yang menimbulkan bau busuk c) Pembakaran sampah dapat menimbulkan pencemaran undara dan bahaya kebakaran yang lebih luas d) Pembuangan sampah ke dalam saluran pembuangan air akan menyebabkan aliran air terganggu dan saluran air menjadi dangkal. e) Apabila musim hujan datang, sampah yang menumpuk dapat menyebabkan banjir dan mengakibatkan penccemaran pada sumber air permukaan atau sumur dangkal. f) Air banjir dapat mengakibatkan kerusakan pada fasilitas masyarakat seperti jalan, jembatan, dan saluran air. Menurut Pratiwi (2016), setiap aktifitas manusia pasti akan menghasilkan limbah atau sampah. Oleh karena itu, menghindari terjadi nya sampah sangatlah tidak mungkin, namun perlu adanya penanganan terhadap masalah sampah ini karena sampah memiliki efek 
negatif terhadap kesehatan dan lingkungan. Salah satu solusi untuk penanggulangan sampah ini adalah ecobrick.

Ecobrick adalah usaha pemanfaatan sampah non organik seperti plastik, kresek dengan dimanfaatkan menjadi satu di dalam botol plastik dan bisa digunakan untuk membuat berbagai alat yang berguna dan bemanfaat (Chien dkk, 2012: 80). Jupri, dkk (2019) Ecobrick adalah salah satu usaha kreatif bagi penanganan sampah plastik, fungsinya bukan untuk menghancurkan sampah plastik, melainkan untuk memperpanjang usia plastik tersebut dan mengolahnya menjadi sesuatu yang berguna, yang bisa dipergunakan bagi kepentingan manusia pada umumnya. Menurut Fauzi, et al (2020) ecobrick adalah salah satu cara penanganan limbah plastik dengan cara mengemas plastik yang bersih dan kering ke dalam botol plastik hingga kerapatan yang ditentukan. Saat ini produk ecobrick dibentuk menjadi sesuatu yang berguna seperti kursi, meja, hingga pengganti batu bata dalam pembuatan rumah (Asih \& Fitriani, 2018; Fauzi et al., 2019). Selain itu, ecobrick segi estetika dan ekonomi dapat menunjang kehidupan masyarakat perkotaan, seperti penggunaan ecobrick untuk pot tanaman di rumah, sebagai pajangan, bahan membuat kolam ikan dan lain sebagainya (Abdullah \& Jamaai, 2016: 20-24). Ecobrick sangat mudah sekali pengerjaannya cukup dengan memasukkan plastik-plastik bekas yang sudah dibersihkan sebelumnya dengan pencucian dan pengeringan kedalam botol plastik bekas hingga padat dan menjadi keras

Apriyani, dkk (2020) Anak sekolah perlu diberikan pemahaman dan pembiasaan terhadap pengolahan sampah ini sehingga dapat menjadi pribadi yang dapat menjaga kebersihan lingkungan mulai dari membangun kebiasaan membuang sampah pada tempatnya hingga mampu memanfaatkan kembali sampah yang masih dapat digunakan/diolah kembali. Pengelolaan sampah dikenal dengan istilah "prinsip 3R yaitu Reduce (mengurangi), Reuse (Menggunakan/memanfaatkan kembali), dan Recycle (Mendaur ulang). Oleh karena itu, pengabdian kepada masyarakat yang akan dilakukan nanti difokuskan kepada bagaimana memberikan pengenalan dan pemamahan tentang ecobrick terhadap siswa SMP agar mampu mengolah sampah menjadi sesuatu yang lebih berguna. Sehingga pada akhirnya siswa memahami bahwa sampah bukan hanya sekedar limbah, tetapi dapat dimanfaatkan kembali untuk kebutuhan manusia.

\section{Metode Pelaksanaan}

Metode Pelaksanaan kegiatan Pengabdian kepada Masyarakat ini adalah pertama, meminta izin terlebih dahulu dengan pihak sekolah SMPN 7 Kota Ternate serta berdiskusi 
tentang alur pelaksanaan kegiatan. Kedua, pelaksanaan kegiatan pengabdian dimulai dengan pembukaan oleh pihak sekolah, pemaparan materi tentang ecobrick oleh tim pengabdian yaitu penjelasan tentang sampah, jenis-jenis sampah, dampak negatif sampah, dan penanggulangan masalah sampah melalui teknik ecobrick. Ketiga, sesi tanya jawab dengan peserta/siswa jika ada penjelasan yang kurang dipahami. Keempat, Demonstrasi langsung cara membuat ecobrick yang sederhana.

\section{Hasil dan Pembahasan}

Deskripsi tentang rangkaian pelaksanaan kegiatan Pengabdian kepada Masyarakat melalui pengenalan Ecobrick di Sekolah Sebagai Upaya Penanggulangan Masalah Sampah adalah sebagai berikut:

1) Penjelasan mengenai siklus sampah, jenis-jenis sampah, dampak sampah

Kegiatan ini sebagai kegiatan inti dimana tim secara bergantian menjelaskan materi sampah terlebih dahulu, silkus sampah, jenis-jenis sampah yaitu sampah organic dan non organik/anorganik beserta contoh masing-masing serta dampak jika masalah sampah tidak diselesaikan segera.

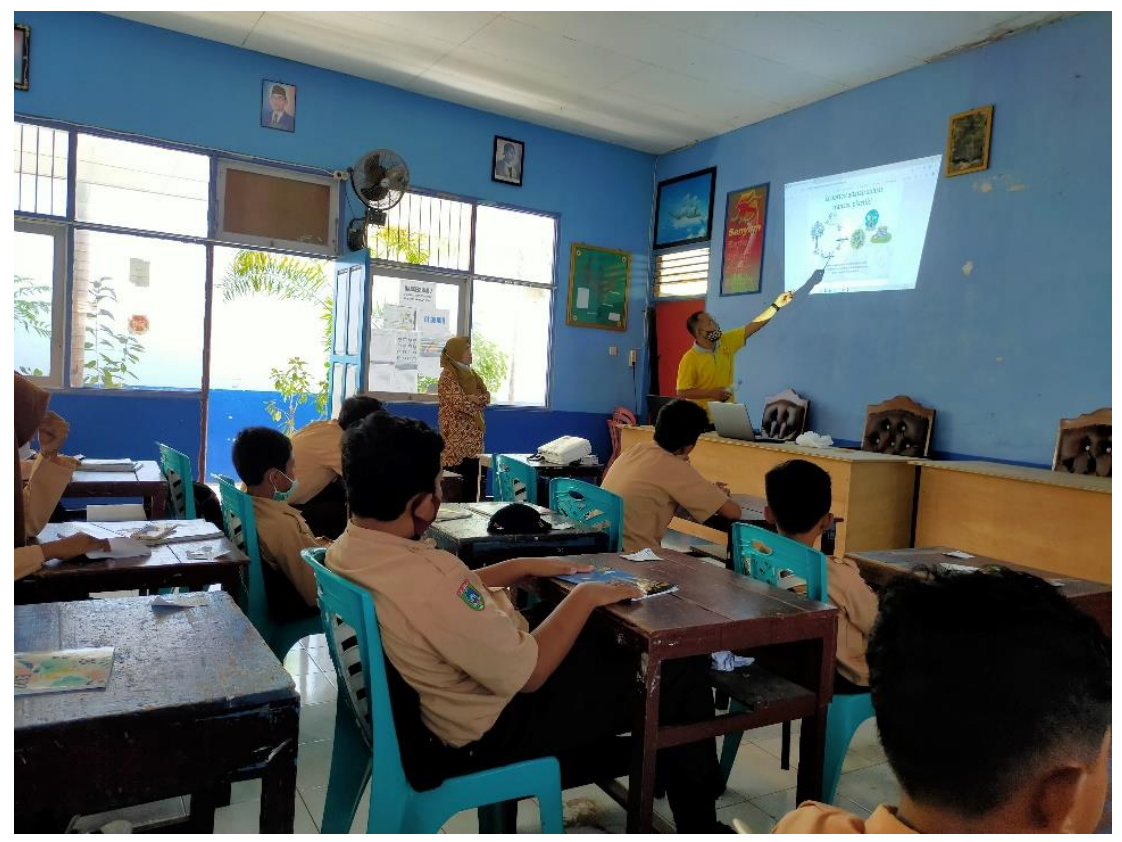

Gambar 1: Penjelasan tentang siklus sampah

2) Pengenalan Ecobrick kepada siswa melalui pemutaran Video

Video yang digunakan dalam pengabdian ini adalah video tentang komunitas yang ada di Bali. Komunitas ini dibentuk sebagai gerakan untuk menanggulangi sampah plastic melalui ecobrick 


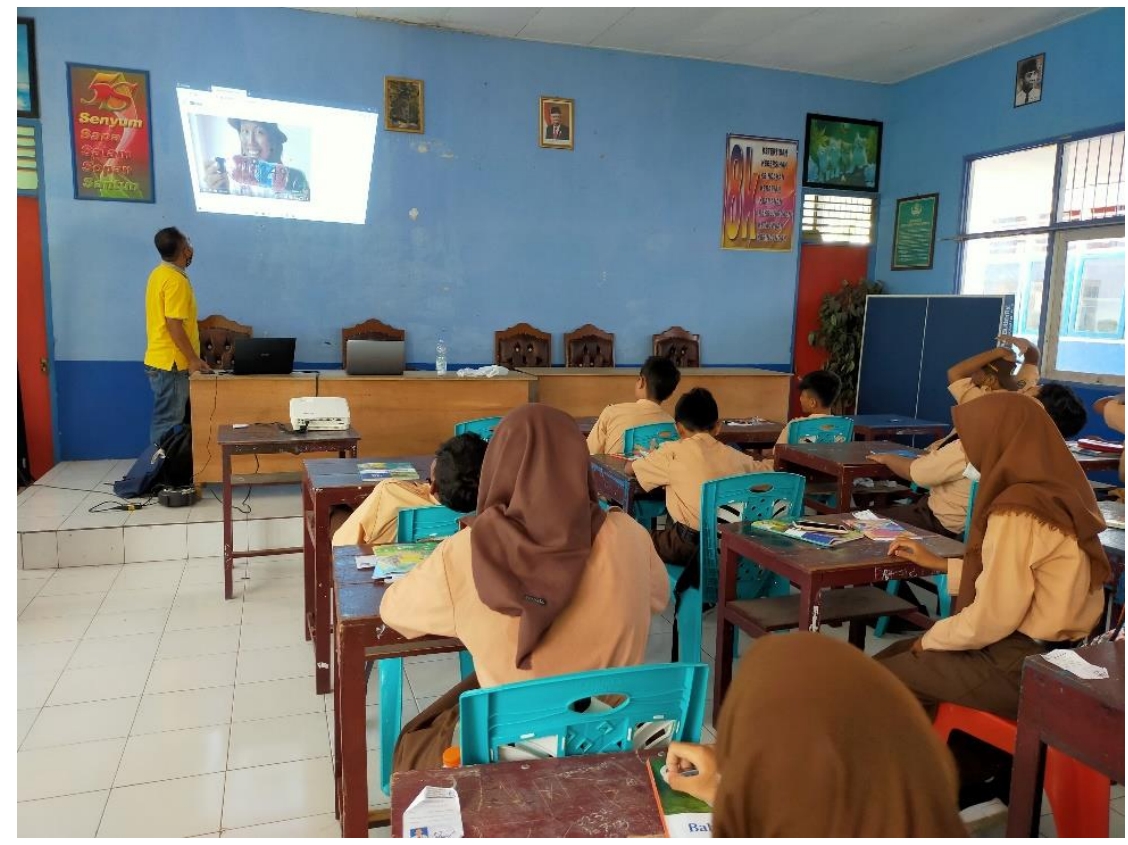

Gambar 2: Pemutaran video tentang ecobrick

3) Sesi tanya jawab dengan peserta

Kegiatan ini bertujuan agar penjelasan dari tim dapat dipahami betul oleh peserta. Peserta dipersilahkan bertanya seputar sampah dan ecobrick.

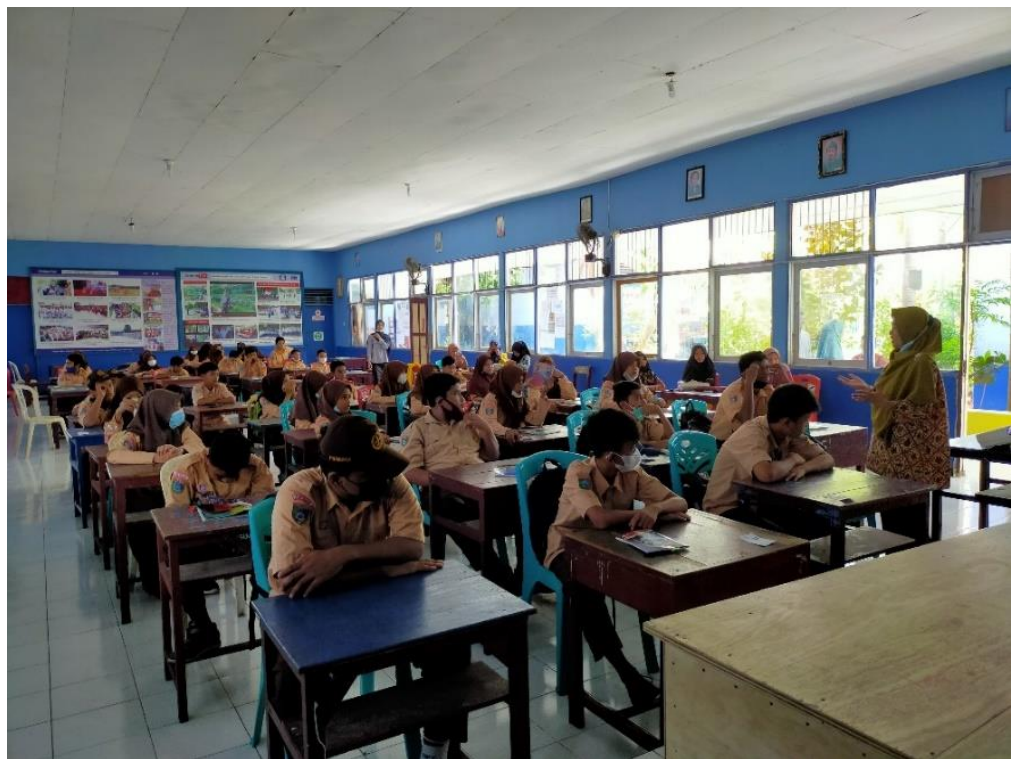

Gambar 3: Peserta bertanya tentang manfaat ecobrick

4) Demonstrasi secara langsung pembuatan ecobrick melalui botol dan sampah plastic

Kegiatan ini dilakukan agar siswa memahami tenatng tahapan membuat ecobrick. Mulai dari mengambil sampah plastik di sekitar kita, kemudian mencuci sampah plastik tersebut 
menggunakan sabun, lalu dijemur hingga kering. Setelah itu, sampah digunting kecil-kecil atau bisa juga tidak digunting. Terakhir memasukkan sampah tersebut ke dalam botol plastik.

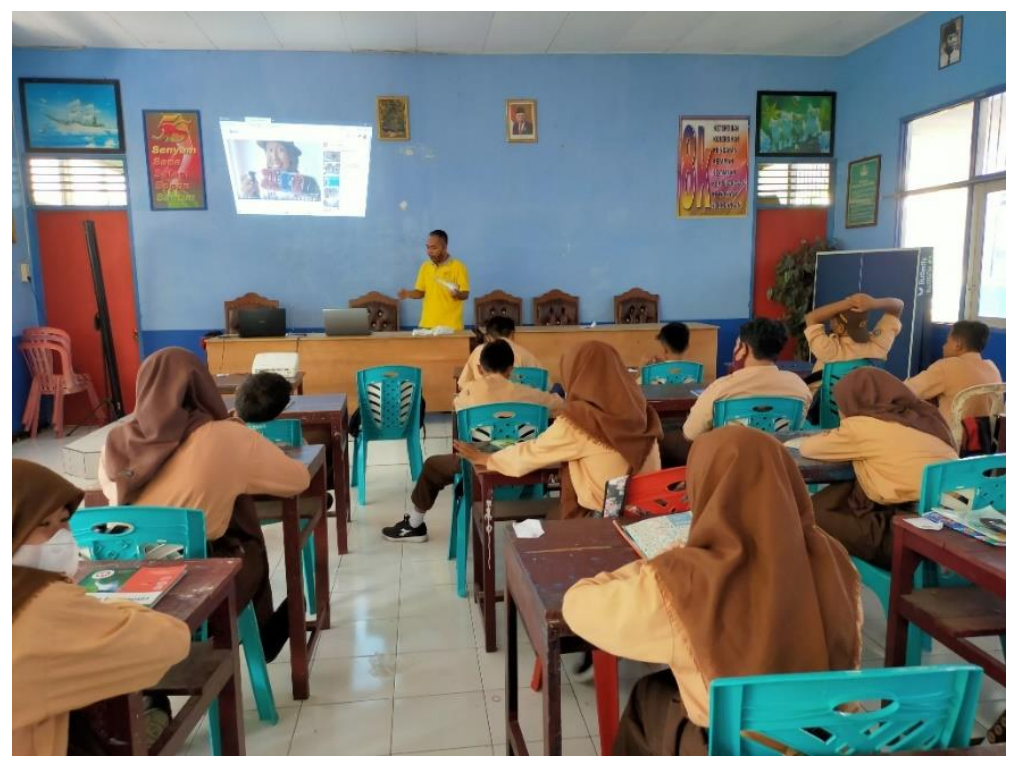

Gambar 4: Demonstasi tahap-tahap membuat ecobrick

\section{Kesimpulan}

Berdasarkan kegiatan di atas dapat disimpulkan bahwa Ecobrick adalah teknik pengelolaan sampah plastik yang terbuat dari botol-botol plastik bekas yang didalamnya telah diisi berbagai sampah plastik hingga penuh kemudian dipadatkan sampai menjadi keras. Ecobrick merupakan salah satu upaya kreatif untuk mengelola sampah plastik menjadi bendabenda yang berguna, mengurangi pencemaran dan racun yang ditimbulkan oleh sampah plastik. Adapun kegiatan pengabdian kepada masyarakat ini bertujuan untuk mengedukasi para siswa di sekolah agar tidak hanya membuang sampah pada tempatnya, namun kesadaran untuk memikirkan pengolahan sampah tersebut juga sangat berguna sebagai salah satu upaya dalam menanggulangi sampah plastik dan menjauhkan lingkungan sekitar dari bahaya sampah plastik

\section{Referensi}

Abdullah, H., \& Jamaai, A. K. (2016). Properties of eco-brick manufactured using kenaf fibre as matrix. Journal of Applied and Physical Sciences, 2(1), 20-24

Asih, H.M., \& Fitriani, S. (2018). Penyusunan Standard Operating Procedure (SOP) Produksi Inovasi Ecobrick. Jurnal Ilmiah Teknik Industri, 17(2), 144. https:// doi.org/10.23917/jiti.v17i2.6832

Apriyani, A., Putri, M., \& Wibowo, S. (2020). Pemanfaatan sampah plastik menjadi ecobrick. $\begin{array}{llll}\text { Masyarakat Berdaya } & \text { Inovasi, }\end{array}$ 
doi:https://doi.org/10.33292/mayadani.v1i1.11

Chandra, B. (2006). Pengantar Kesehatan Lingkungan. EGC. Jakarta

Chien, C. C., Lu, Y. S., Liou, Y. J., \& Huang, W. J. (2012). Application of waste bamboo materials on produced eco-brick. Journal of Shanghai Jiaotong University (Science), 17(3), 380-384.

Fauzi, M., Sumiarsih, E., Adriman, Rusliadi, Hasibuan, I.F., Fista, A., \& Hermawita, A. (2019). Ecobrick Solusi Sampah Plastik Masa Kini. UR Press.

Fauzi, M., Sumiarsih, E., Adriman., Rusliadi, \& Hasibuan, I.F. (2020). Pemberdayaan masyarakat melalui pelatihan pembuatan ecobrick sebagai upaya mengurangi sampah plastik di Kecamatan Bunga Raya. Riau Journal of Empowerment, 3(2), 87-96. https://doi.org/10.31258/raje.3.2.87-96

Jupri, A., Prabowo, AJ., Aprilianti, BR., Unnida. D. (2019). Pengelolaan Limbah Sampah Plastik Dengan Menggunakan Metode Ecobrick Di Desa Pesanggrahan. Prosiding PEPADU 1 (1), 341-347

Nugroho P. 2013. Panduan Membuat Kompos Cair. Jakarta: Pustaka baru Press.

Pratiwi, D. (2016). Pengenalan pengolahan sampah untuk anak-anak taman kanak-kanak melalui media banner. Jurnal Bioedukasi, http://dx.doi.org/10.24127/bioedukasi.v7i1.491

Sucipto, C.D. (2012). Teknologi Daur Ulang Sampah. Yogyakarta: Gosyen Publishing. 